\title{
The Impact of Cost Uncertainty on Cournot Duopoly Game with Concave Demand Function
}

\author{
S. S. Askar ${ }^{1,2}$ \\ ${ }^{1}$ Department of Statistics and Operations Researches, College of Science, King Saud University, P.O. Box 2455, \\ Riyadh 11451, Saudi Arabia \\ ${ }^{2}$ Department of Mathematics, Faculty of Science, Mansoura University, Mansoura 35516, Egypt
}

Correspondence should be addressed to S. S. Askar; s.e.a.askar@hotmail.co.uk

Received 8 September 2013; Revised 24 October 2013; Accepted 24 October 2013

Academic Editor: Pu-yan Nie

Copyright (c) 2013 S. S. Askar. This is an open access article distributed under the Creative Commons Attribution License, which permits unrestricted use, distribution, and reproduction in any medium, provided the original work is properly cited.

It is reported in the literature that the most fundamental idea to address uncertainty is to begin by condensing random variables. In this paper, we propose Cournot duopoly game where quantity-setting firms use nonlinear demand function that has no inflection points. A random cost function is introduced in this model. Each firm in the model wants to maximize its expected profit and also wants to minimize its uncertainty by minimizing the cost. To handle this multiobjective optimization problem, the expectation and worst-case approaches are used. A model of two rational firms that are in competition and produce homogenous commodities is introduced using an unknown demand function. The equilibrium points of this model are obtained and their dynamical characteristics such as stability, bifurcation, and chaos are investigated. Complete stability and bifurcation analysis are provided. The obtained theoretical results are verified by numerical simulation.

\section{Introduction}

In economic markets, competed firms often face considerable uncertainty upon their productions. This uncertainty may be concerned with information on the exact demand function, rivals' costs, or even components of firms own production cost. The effects of uncertainty in the optimizing behavior of economic models have been previously examined by many researchers. Sandmo [1] has introduced a systematic study of the theory of firms under a price uncertainty and risk aversion. In [2], some properties of class of models involving optimization under uncertainty have been analyzed. Dardononi [3] has presented the impact of uncertainty on an agent that has a two-argument utility function under plausible normality conditions. A simple noncooperative game with common uncertainty in which the firms have two-argument utility functions has been discussed by Gradstein et al. [4]. In [4], the authors have shown that the effect of increased uncertainty on the equilibrium strategies is similar to its effect on the optimal strategy of a single agent.

In the literature, several studies concerning duopolistic models under uncertainty have investigated that in such models each firm is in risk neutral and may share or exchange its information on market uncertainty with its rival [5-11]. In these studies, it has been investigated how market uncertainty with either unknown market demand or unknown constant marginal cost can affect firms' behavior.

Everyone agrees that risk is associated with having to make a decision without fully knowing its consequences, due to future uncertainty, but also knowing that some of those consequences might be bad or at least undesirable relative to others [12]. To many people, the amount of risk in a random variable representing a cost of some kind is the degree of uncertainty in it, that is, how much it deviates from being constant. To other people, risk must be quantified in terms of a surrogate for the overall cost, such as its mean value, median value, or worst possible value [12]. An alternative approach for risk measurement has been introduced in detail by Ahmed et al. [13]. In [13], Ahmed et al. have modeled risk in Cournot game based on multiobjective method. Ahmed et al. [13] have used the standard deviation for modeling risk in Cournot game.

The goal of this paper is to set up a discrete time dynamic Cournot model in which duopoly firms use an unknown 
nonlinear demand function with cost uncertainty. We assume that each firm does not know the other firm's cost function at the time when the output is produced. It is assumed that the cost function used in this model is generated based on a random variable with zero mean and standard deviation equal to one. Therefore, with the given situation of uncertainty, the existence and uniqueness of the equilibrium point and its asymptotic behavior are proved and investigated.

The paper is devoted as follows. In Section 1, an introduction and related works are presented. Next, some basic concepts which can be found elsewhere [14-17] are provided in Section 2 to make the current paper self-contained. The model and the main results are illustrated and discussed in detail in Section 3. Finally, some concluding results are presented.

\section{Basic Concepts}

This section provides some basic concepts that will be used in the sequel.

Definition 1. A payoff is a function $\pi: \mathbb{A} \rightarrow \mathbb{R}$ that associates a numerical value with every action $a \in \mathbb{A}$.

Definition 2. An action $a^{*} \in \mathbb{A}$ is an optimal action if $\pi\left(a^{*}\right) \geq$ $\pi(a)$ for all $a \in \mathbb{A}$.

Definition 3. A solution is called a Pareto-optimal solution if no player's payoff can be increased without decreasing the payoff to the other player. Such solutions are also termed socially efficient or just efficient.

Definition 4. A Nash equilibrium (for the two player games) is a pair of strategies $\left(\sigma_{1}^{*}, \sigma_{2}^{*}\right)$ such that

$$
\begin{array}{ll}
\pi_{1}\left(\sigma_{1}^{*}, \sigma_{2}^{*}\right) \geq \pi_{1}\left(\sigma_{1}, \sigma_{2}^{*}\right), & \forall \sigma_{1} \in \Sigma_{1}, \\
\pi_{2}\left(\sigma_{1}^{*}, \sigma_{2}^{*}\right) \geq \pi_{2}\left(\sigma_{1}^{*}, \sigma_{2}\right), & \forall \sigma_{2} \in \Sigma_{2},
\end{array}
$$

where $\Sigma_{i}$ is the set of all possible strategies for player $i$.

\section{Model and Main Results}

Here, we propose a new demand function that has not been used in the literature before. The purpose of using this function is that the function has no inflection points. In addition, it has been investigated elsewhere that when the monopolistic firms use such function in the market it seems that Nash equilibrium goes from stability through double bifurcation to chaos [18]. To start our work in the present paper, we consider that the market includes two firms producing homogeneous commodities to sale in the market. Let $q_{i}^{t}$ be the output of the firm $i, i=1,2$, at discrete time $t=0,1,2, \ldots$. This simple situation is called a Cournot duopoly game. Apparently, one should be aware that those two firms are in conflict (more precisely, in competition). Now, let us assume that both firms adopt the following inverse demand function:

$$
P\left(Q_{t}\right)=a-b Q_{t}^{4}
$$

where $Q_{t}=\sum_{i=1}^{2} q_{i}^{t}, q_{i}, i=1,2$, is the quantity of commodity produced by the firm $i$. In addition, $a, b$ are positive constants.
Few approaches of uncertainty in multiobjective optimization problems have been reported in the literature [19]. The most fundamental idea to address uncertainty in such problems is to begin by condensing random variables. Rockafellar [19] has reported shortcomings on those approaches. In this section, we apply the expectation and worst-case approaches described by Rockafellar [19]. Let us now suppose that the two firms use the following random cost function:

$$
C\left(q_{i}^{t}\right)=\left(c+\gamma \varepsilon_{i}\right) q_{i}^{t}, \quad i=1,2,
$$

where $c \geq 0$ is the fixed marginal cost, $\varepsilon_{i} \geq 0$, and $\gamma$ is a random variable with zero mean and variance equal to 1 . The main aim of each firm is to maximize its following profit:

$$
\begin{aligned}
& \pi_{1}\left(q_{1}^{t}, q_{2}^{t}\right)=\left(a-c-\gamma \varepsilon_{1}-b Q_{t}^{4}\right) q_{1}^{t}, \\
& \pi_{2}\left(q_{1}, q_{2}\right)=\left(a-c-\gamma \varepsilon_{2}-b Q_{t}^{4}\right) q_{2}^{t} .
\end{aligned}
$$

Now, a repeated Cournot duopoly game is considered. It consists of two bounded rational players (firms) in which they update their production strategies at discrete time periods. They use an adjustment mechanism based on a local estimation of the marginal profit. This dynamical adjustment mechanism is described by the following dynamical system:

$$
q_{i}^{t+1}=q_{i}^{t}+\alpha\left(q_{i}^{t}\right) \frac{\partial \pi_{i}}{\partial q_{i}^{t}}, \quad i=1,2 .
$$

It is known elsewhere $[13,18]$ the significance of speed of adjustment $\alpha\left(q_{i}^{t}\right)$. It is a positive function which gives the extent of production variation of $i$ th firm following a given profit signal. Moreover, it captures the fact that relative effort variations are proportional to the marginal profit.

Here, two scenarios are considered as follows.

Scenario 1 (worst-case approach). This case relies on determining the worst that might happen. For example, if the uncertainty in $\gamma$ has to do with market fluctuation due to future circumstances, there may be no available choice of the fixed cost $c$ that guarantees absolute compliance. Therefore, if the target of a firm is to maximize its profit, it may have to live with a balance between the practicalities of the fixed cost $c$ and the chance that fluctuation of the market could be controlled by some extreme efforts.

$$
\begin{aligned}
& \text { Substituting (4) in (5), one gets } \\
& \qquad \begin{array}{l}
q_{1}^{t+1}=q_{1}^{t}+k q_{1}^{t}\left(a-c-\gamma \varepsilon_{1}-4 b q_{1}^{t} Q_{t}^{3}-b Q_{t}^{4}\right) \\
q_{2}^{t+1}=q_{2}^{t}+k q_{2}^{t}\left(a-c-\gamma \varepsilon_{2}-4 b q_{2}^{t} Q_{t}^{3}-b Q_{t}^{4}\right)
\end{array}
\end{aligned}
$$

where $\varepsilon_{i}>0, i=1,2$, is the cost control parameters. In the literature many authors have assumed a constant speed of adjustment inducing that a positive variation of profits will make the monopolist to change the quantity in the same direction from that in the previous one. Therefore, no changes will occur if profits are constant. Bischi et al. [20, 21] have chosen a speed of adjustment that is linear function of the quantities produced. In this paper, we assume a linear speed 


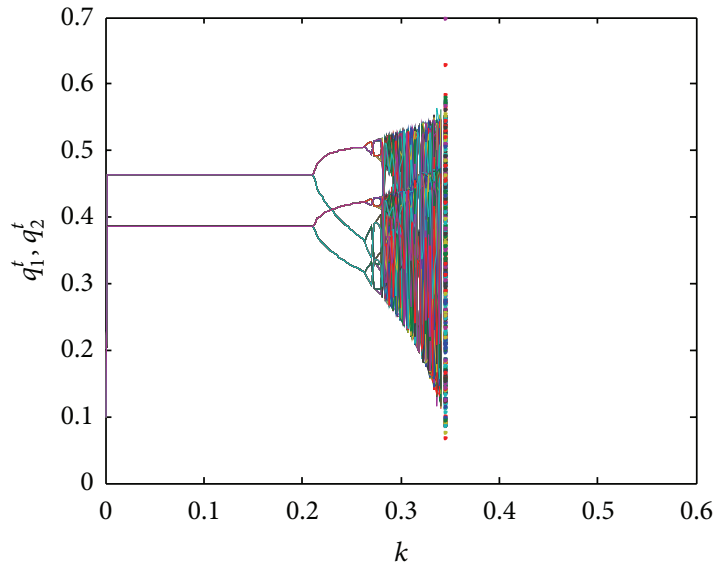

(a)

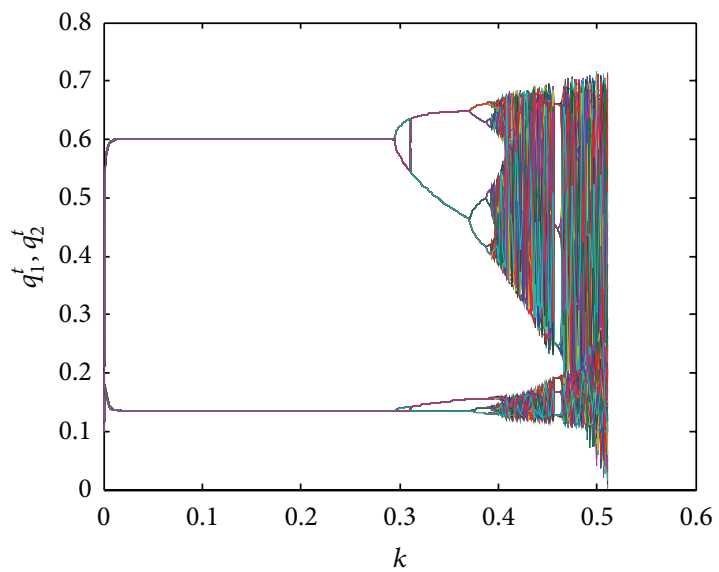

(b)

FIGURE 1: Bifurcation and chaos of the map (6) at the parameters: (a) $a=3, b=1.5, c=0.3, \varepsilon_{1}=0.3, \varepsilon_{2}=0.7$, and $\gamma=0.7254$; (b) $a=3$, $b=1.5, c=0.3, \varepsilon_{1}=0.3, \varepsilon_{2}=0.7$, and $\gamma=2.7694$.

of adjustment, where $\alpha\left(q_{i}^{t}\right)=k q_{i}^{t}, i=1,2, k$ is constant. The above system has the following equilibrium points:

$$
\begin{aligned}
E_{o}=(0,0), \quad E_{1}=\left(\left(\frac{a-c-\gamma \varepsilon_{1}}{5 b}\right)^{1 / 4}, 0\right), & \left(0,\left(\frac{a-c-\gamma \varepsilon_{2}}{5 b}\right)^{1 / 4}\right), \\
E_{2}= & \left(\frac{4(a-c)-\gamma\left(5 \varepsilon_{1}-\varepsilon_{2}\right)}{24\left[6 b\left(2 a-2 c-\gamma\left(\varepsilon_{1}+\varepsilon_{2}\right)\right)^{3}\right]^{1 / 4}},\right. \\
& \left.\frac{4(a-c)+\gamma\left(\varepsilon_{1}-5 \varepsilon_{2}\right)}{24\left[6 b\left(2 a-2 c-\gamma\left(\varepsilon_{1}+\varepsilon_{2}\right)\right)^{3}\right]^{1 / 4}}\right) .
\end{aligned}
$$

The fixed points $E_{1}$ and $E_{2}$ can be denoted as monopoly fixed points such that $a>c+\gamma \varepsilon_{i}, i=1,2$. Assuming $a>c+$ $\gamma \varepsilon_{i}, i=1,2$, guarantees positive equilibrium productions. To get more insights about these two monopolistic points, some analytical and numerical discussions are carried out.

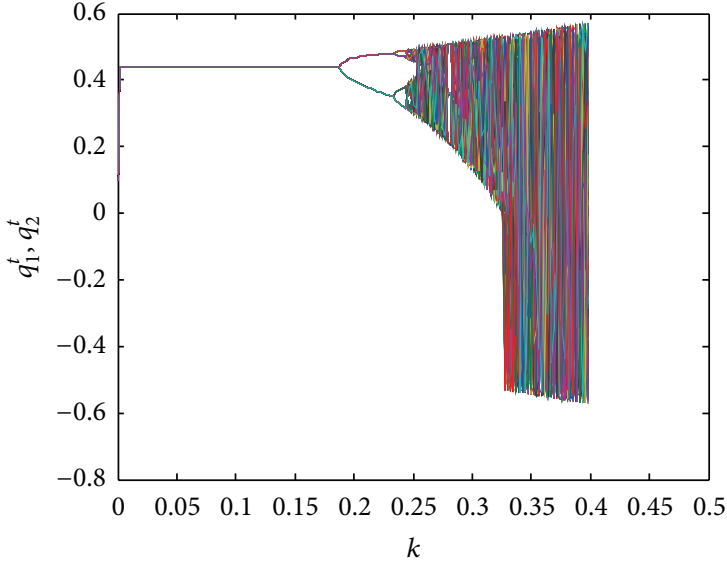

(a)

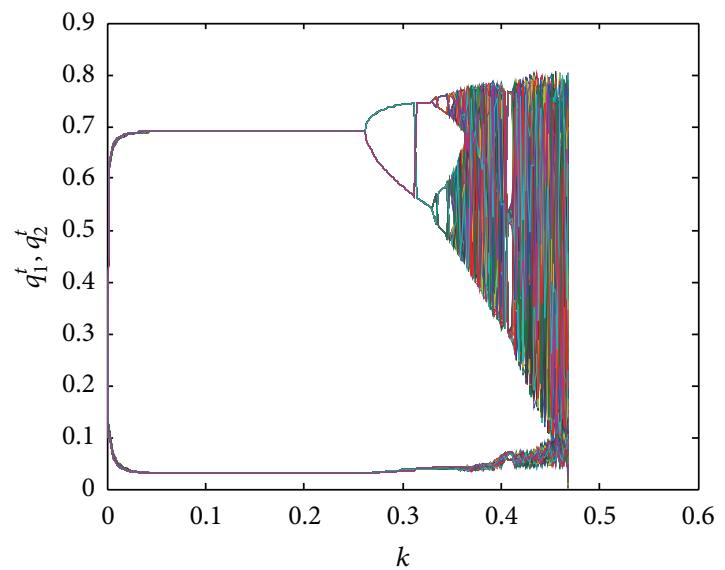

(b)

FIgURE 2: Bifurcation and chaos of the map (6) at the parameters: (a) $a=3, b=1.5, c=0.3, \varepsilon_{1}=2, \varepsilon_{2}=6$, and $\gamma=0.3192$; (b) $a=3$, $b=1.5, c=0.3, \varepsilon_{1}=2, \varepsilon_{2}=6$, and $\gamma=.3714$.

Proposition 5. Letting $a>c+\gamma \varepsilon_{i}, i=1,2$, then

(i) the fixed point $E_{\mathrm{O}}$ is a repelling node,

(ii) the monopoly point $E_{1}$ is stable if $k<2 /\left(\gamma \varepsilon_{2}-\right.$ $\left.(1 / 5)\left(4 a-4 c+\gamma \varepsilon_{1}\right)\right)$,

(iii) the monopoly point $E_{2}$ is stable if $k<2 /\left(\gamma \varepsilon_{1}-\right.$ $\left.(1 / 5)\left(4 a-4 c+\gamma \varepsilon_{2}\right)\right)$.

Proof. The proof of the above proposition is based on the standard analysis of the eigenvalues as follows. It is easy to check that the point $E_{o}$ is an unstable point. The Jacobian matrix at the point $E_{1}$ becomes

$$
\left(\begin{array}{cc}
1+4 k \gamma \varepsilon_{1}-4 k(a-c) & -\frac{16 k}{5}\left(a-c-\gamma \varepsilon_{1}\right) \\
0 & 1-k \gamma \varepsilon_{2}+\frac{k}{5}\left(4 a-4 c+\gamma \varepsilon_{1}\right)
\end{array}\right)
$$

whose eigenvalues are $\lambda_{1}=1+4 k \gamma \varepsilon_{1}-4 k(a-c)$ and $\lambda_{2}=1-$ $k \gamma \varepsilon_{2}+(k / 5)\left(4 a-4 c+\gamma \varepsilon_{1}\right)$. It is easy to see that these eigenvalues are real given $a>c+\gamma \varepsilon_{i}, i=1,2$. Hence, for the point $E_{1}$ to 


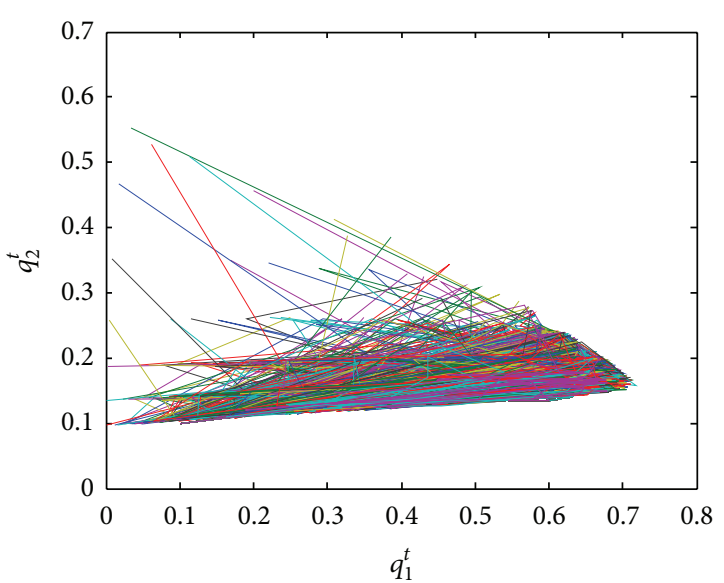

(a)

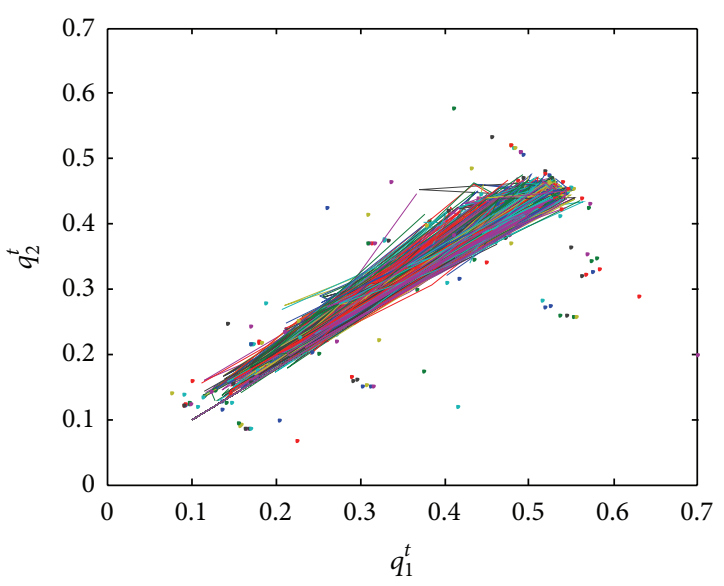

(b)

FIGURE 3: The relationship between $q_{1}^{t}$ and $q_{2}^{t}$ at the parameters: (a) $a=3, b=1.5, c=0.3, \varepsilon_{1}=2, \varepsilon_{2}=6$, and $\gamma=2.7694$; (b) $a=3$, $b=1.5, c=0.3, \varepsilon_{1}=2, \varepsilon_{2}=6$, and $\gamma=0.7254$.

be stable, the eigenvalues should satisfy $\left|\lambda_{i}\right|<1, i=1,2$, that is, $k<1 /\left(2\left(a-c-\gamma \varepsilon_{1}\right)\right)<2 /\left(\gamma \varepsilon_{2}-(1 / 5)\left(4 a-4 c+\gamma \varepsilon_{1}\right)\right)$, which can be reduced to $k<2 /\left(\gamma \varepsilon_{2}-(1 / 5)\left(4 a-4 c+\gamma \varepsilon_{1}\right)\right)$. For the stability of the point $E_{2}$, the same considerations and arguments hold and this completes the proof. Regarding $E_{3}$, numerical simulation is employed.

To illustrate the stability of the point $E_{3}$, some numerical cases are assumed to make the discussion economically interpreted. Let us assume that the system's parameters are given as follows: $a=3, b=1.5, c=0.3, \varepsilon_{1}=0.3, \varepsilon_{2}=$ 0.7 , and a randomly selected value $\gamma=0.7254$. We graphically show how the dynamical behavior of the map (6) changes for different values of the parameter $k$. Figure 1(a) presents different values of the quantities for different value of the parameter $k$. It is easily illustrated that both quantities move from stability through a sequence of period doubling bifurcation to chaos. It is also noted that the marginal cost at the market should be less than the fixed price $\left(a>c+\gamma \varepsilon_{i}, i=1,2\right)$.

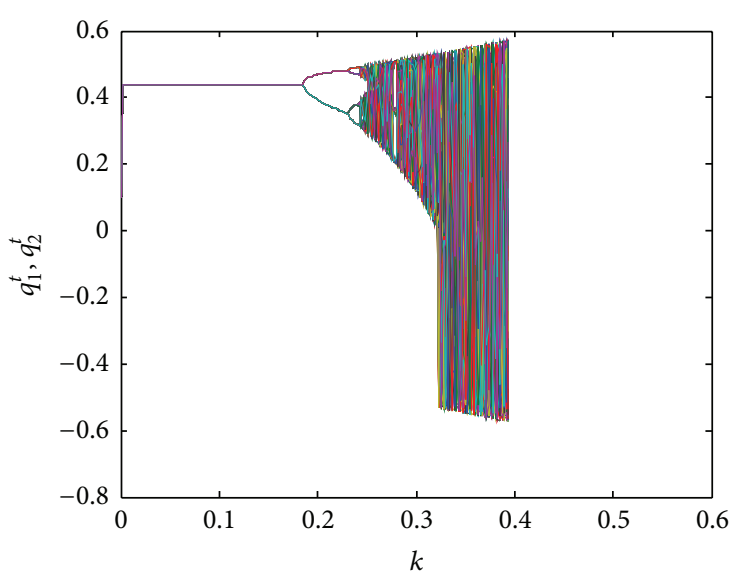

(a)

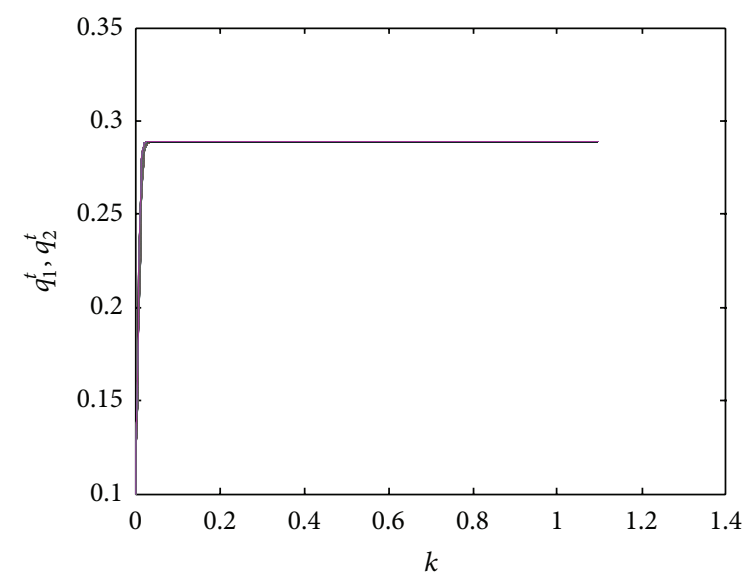

(b)

Figure 4: Bifurcation and chaos of the map (9) at the parameters: (a) $a=3, b=1.5, c=0.3$; (b) $a=0.5, b=0.3, c=0.4$.

Interestingly, it is numerically observed that when $a \leq 1, b<$ $0.5, c<0.3$, and the other parameters are left without change the period doubling bifurcation of the map (6) is going to be reduced. Figures 1(b) and 2 simulate the dynamic behavior of the map for different values of the parameters. Figure 3 shows the chaotic behavior of the relationship between quantities produced by both firms at different value of the parameter $\gamma$.

Scenario 2 (expectation approach). Expectation is primarily suitable for situations where the interest lies in long-range operation and where stochastic ups and downs can safely average out. Since the expectation of $\gamma$ is zero, (3) becomes $C\left(q_{i}^{t}\right)=c q_{i}^{t}, i=1,2$. With this information, the system (6) is reduced to the following form:

$$
\begin{aligned}
& q_{1}^{t+1}=q_{1}^{t}+k q_{1}^{t}\left(a-c-4 b q_{1}^{t} Q_{t}^{3}-b Q_{t}^{4}\right), \\
& q_{2}^{t+1}=q_{2}^{t}+k q_{2}^{t}\left(a-c-4 b q_{2}^{t} Q_{t}^{3}-b Q_{t}^{4}\right) .
\end{aligned}
$$


That admits the following fixed points:

$$
\begin{aligned}
& E_{o}=(0,0), \quad E_{1}=\left(\left(\frac{a-c}{5 b}\right)^{1 / 4}, 0\right), \\
& E_{2}=\left(0,\left(\frac{a-c}{5 b}\right)^{1 / 4}\right), \\
& E_{3}=\left(\left(\frac{a-c}{48 b}\right)^{1 / 4},\left(\frac{a-c}{48 b}\right)^{1 / 4}\right) .
\end{aligned}
$$

The proof of stability and instability conditions of the above fixed points are similar to those in Proposition 5. Here we briefly give only numerical simulation for the dynamical behavior of the system (9) at certain value parameters. Figure 4 illustrates the dynamic behavior of the system (9) at those parameters.

\section{Conclusions}

In this paper, we have proposed a Cournot duopoly model based on an uncertain cost and a demand function without inflection point. For this model, the existence and uniqueness of the equilibrium have been proved. The asymptotic behavior of the equilibrium point has been investigated. Complete stability and bifurcation analysis have been illustrated. The obtained theoretical results have been verified by numerical simulation.

\section{Acknowledgment}

This project was supported by King Saud University, Deanship of Scientific Research, College of Science Research Center.

\section{References}

[1] A. Sandmo, "On the theory of the competitive firm under price uncertainty," American Economic Review, vol. 61, no. 1, pp. 6573, 1971.

[2] G. Feder, "The impact of uncertainty in a class of objective functions," Journal of Economic Theory, vol. 16, no. 2, pp. 504$512,1977$.

[3] V. Dardononi, "Optical choice under uncertainty: the case of two-argument utility function," Economic Journal, vol. 98, pp. 429-450, 1988.

[4] M. Gladstein, S. Nitzan, and S. Slutsky, "The effects of uncertainty on interactive behavior," Economic Journal, vol. 102, pp. 554-561, 1992.

[5] R. N. Clarke, "Collusion and the incentives for information sharing," Bell Journal of Economics, vol. 14, pp. 383-394, 1983.

[6] E. Gal-Or, "Information transmission-Cournot and Bertrand equilibria," The Review of Economic Studies, vol. 53, no. 1, pp. 85-92, 1986.

[7] A. Kirby, "Trade associations as information exchange mechanism," The RAND Journal of Economics, vol. 19, no. 1, pp. 138$146,1988$.

[8] L. Li, "Cournot oligopoly with information sharing," The RAND Journal of Economics, vol. 16, no. 4, pp. 521-536, 1985.

[9] R. M. Cyert and M. H. Degroot, "Interfirm learning and the kinked demand curve," Journal of Economic Theory, vol. 3, no. 3, pp. 272-287, 1971.
[10] R. M. Cyert and M. H. Degroot, "An analysis of cooperation and learning in duopoly context," American Economic Review, vol. 63, no. 1, pp. 24-37, 1973.

[11] A. P. Kirman, "Learning by firms about demand conditions," in Adaptive Economic Models, H. Day and T. Groves, Eds., pp. 137156, Academic Press, New York, NY, USA, 1975.

[12] R. T. Rockafellar, "Coherent approaches to risk in optimization under uncertainty," Informs, vol. 13, pp. 38-61, 2007.

[13] E. Ahmed, A. S. Hegazi, and A. T. Abdel-Hafiz, "On multiobjective oligopoly," Nonlinear Dynamics, Psychology, and Life Sciences, vol. 7, no. 2, pp. 205-219, 2003.

[14] D. Fudenberg and D. Levine, The Theory in Learning in Games, MIT Press, Cambridge, Mass, USA, 1998.

[15] J. N. Webb, Game Theory: Decisions, Interaction and Evolution, Springer Undergraduate Mathematics Series, Springer, London, UK, 2007.

[16] Y. Liu, Nash based strategies for the control of extended complex systems [Ph.D. thesis], Pittsburg University, 2003.

[17] Y. Collette and P. Siarry, Multi-Objective Optimisation: Principles and Case Studies, Springer, Berlin, Germany, 2003.

[18] S. S. Askar, "On complex dynamics of monopoly market," Economic Modelling, vol. 32, pp. 586-598, 2013.

[19] R. T. Rockafellar, "Coherent approaches to risk in optimization under uncertainty," Informs, vol. 13, pp. 38-61, 2007.

[20] G.-I. Bischi, M. Gallegati, and A. Naimzada, "Symmetry-breaking bifurcations and representative firm in dynamic duopoly games," Annals of Operations Research, vol. 89, pp. 253-272, 1999.

[21] G.-I. Bischi, M. Kopel, and A. Naimzada, "On a rent-seeking game described by a non-invertible iterated map with denominator," Nonlinear Analysis: Theory, Methods \& Applications, vol. 47, no. 8, pp. 5309-5324, 2001. 


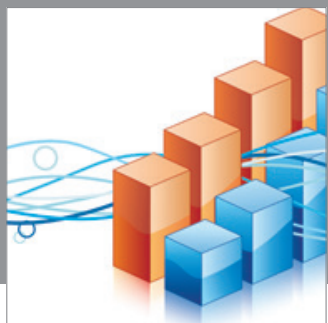

Advances in

Operations Research

mansans

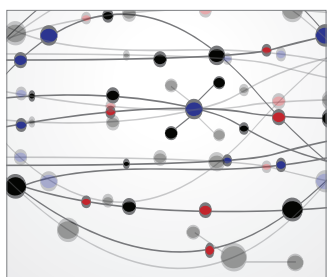

The Scientific World Journal
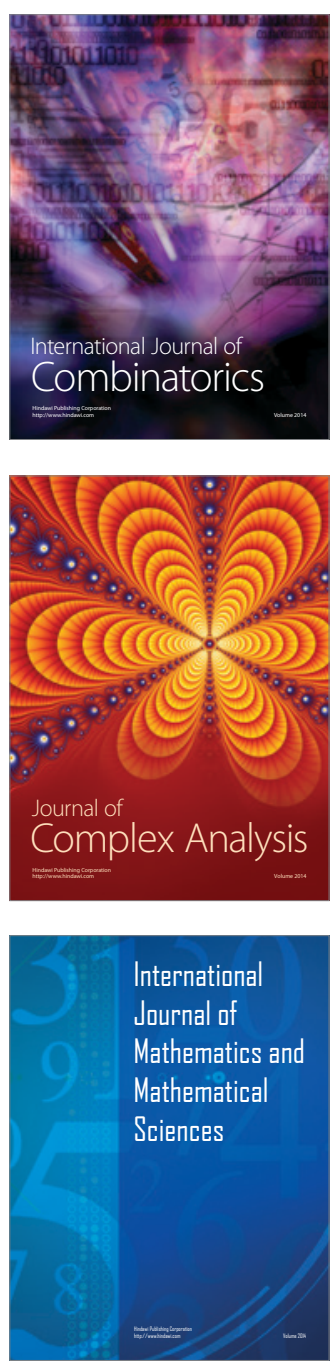
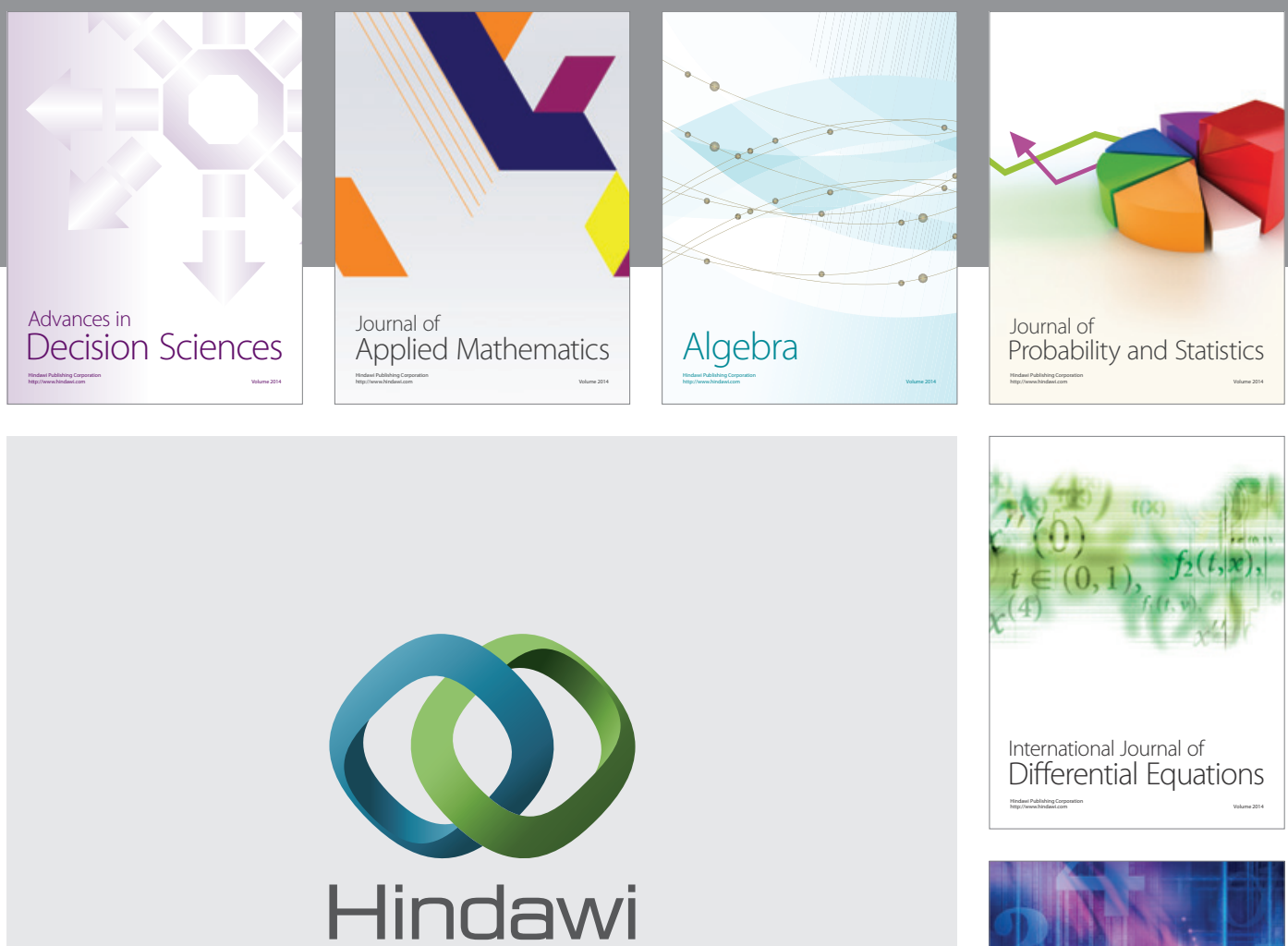

Submit your manuscripts at http://www.hindawi.com
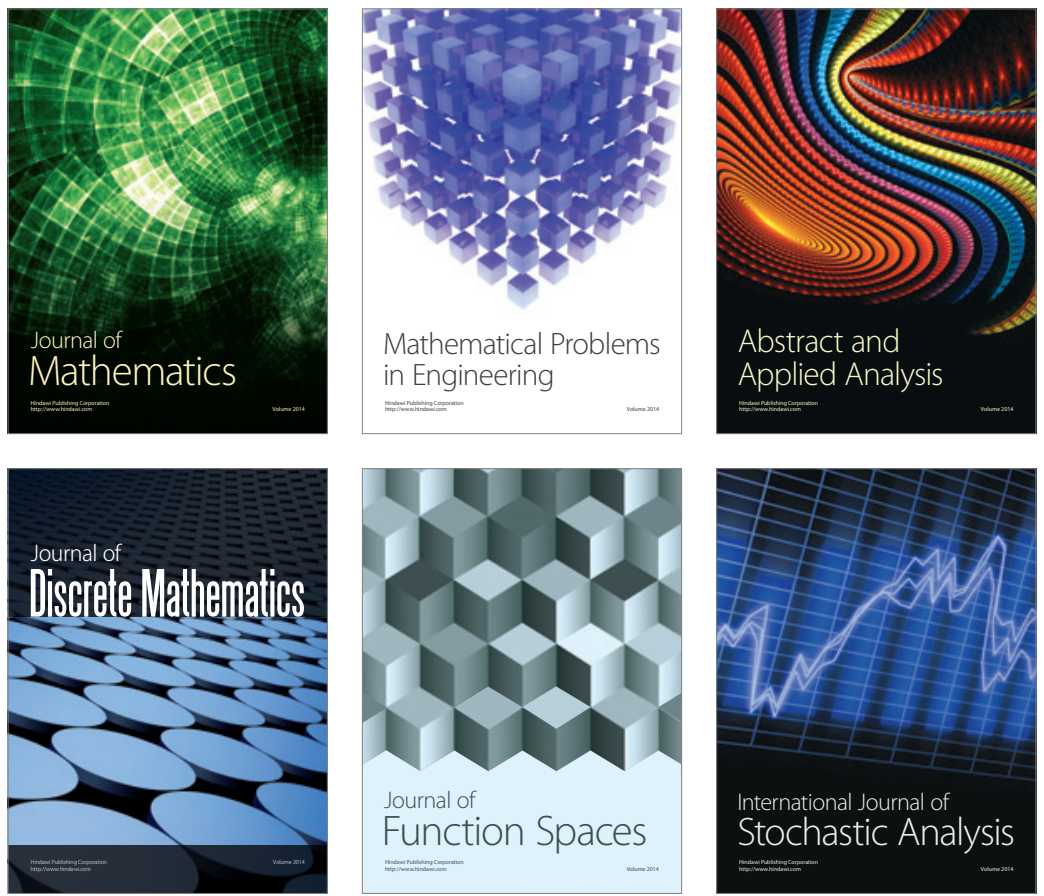

Journal of

Function Spaces

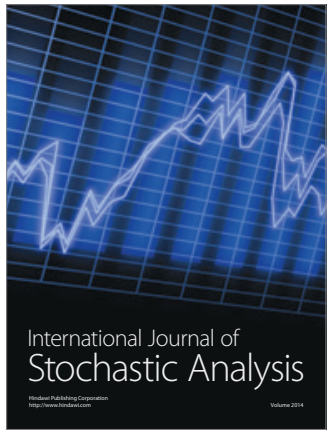

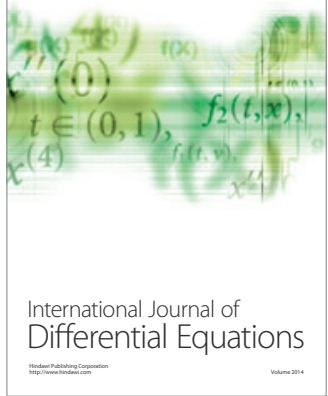
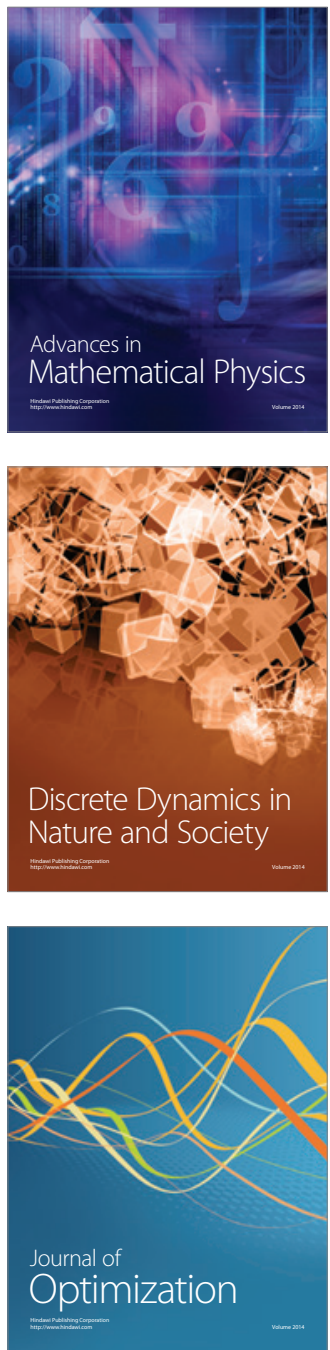